\title{
EFEITO DA SECAGEM DE BRACHIARIA BRIZANTHA CV. MARANDU SOBRE A HIDRÓLISE ENZIMÁTICA DE SEUS POLISSACARÍDEOS
}

\author{
J.A. DE CARVALHO ${ }^{1}$, M.A. CARVALHO ${ }^{2}$, R. GAMBETTA ${ }^{3}$, T.F. PACHECO ${ }^{3}$, T.D. MENDES ${ }^{3}$, \\ E.L. SCHULTZ ${ }^{3}$, M.C.T. DAMASO ${ }^{3}$, D.S.R. GAMBETTA ${ }^{3}$ \\ ${ }^{1}$ Instituto Federal de Educação, Ciência e Tecnologia do Mato Grosso \\ ${ }^{2}$ Embrapa Cerrados \\ ${ }^{3}$ Embrapa Agroenergia \\ E-mail para contato: dasciana.rodrigues@embrapa.br
}

\begin{abstract}
RESUMO - A eficácia da hidrólise enzimática da biomassa é influenciada pela umidade da amostra. Alguns pré-tratamentos químicos podem reduzir/eliminar este efeito. $\mathrm{O}$ objetivo deste trabalho foi avaliar o efeito de secagem sobre o pré-tratamento químico e hidrólise enzimática de brachiaria brizantha. A biomassa foi moída e a umidade determinada, $65 \%$, e uma parte desta foi seca até $5 \%$ de umidade. Cada uma destas amostras foi submetida à pré-tratamentos fraco (ácido e base diluídos) e forte (ácido e base concentrados) e depois submetidas à hidrólise enzimática. Os resultados comprovaram que a secagem da biomassa desfavorece a hidrólise, pois o rendimento de açúcares foi de $35 \%$ para a amostra úmida e $2 \%$ para amostra seca. Após pré-tratamento fraco o rendimento para amostra seca, $70 \%$, foi maior do que na amostra úmida, $59 \%$. Quando pré-tratamento forte foi aplicado, os rendimentos de hidrólise para amostras úmida $(95 \%)$ e seca $(92 \%)$ tornaram-se similares. Concluiu-se que o processo de secagem da biomassa não influencia o rendimento de açúcares da hidrólise enzimática se um pré-tratamento químico adequado for aplicado.
\end{abstract}

\section{INTRODUÇÃO}

Um dos pontos-chave para o uso de biomassa na produção de combustíveis e outros químicos renováveis é viabilizar o transporte e/ou armazenamento desta matéria-prima. Um dos principais obstáculos nestas operações é a umidade nas diferentes biomassas, as quais podem atingir até $70 \%$ em água (Athmanathan et al., 2011). Biomassas com elevados teores de água apresentam baixa densidade energética e tornam-se mais susceptíveis à degradação microbiana, desfavorecendo seu transporte e armazenamento (Acharjee et al., 2011; Medic et al., 2012).

A secagem da biomassa pode ser usada para facilitar seu transporte e armazenamento. Entretanto, há estudiosos que defendem o armazenamento da biomassa úmida em silos. Cada uma destas estratégias tem vantagens e desvantagens relacionadas a condições climáticas, degradação microbiana, perda do material no campo, gasto de energia no pré-processamento, digestibilidade do material, risco de incêndio, geração de resíduos, etc. (Li et al., 2011; Miao et al., 2012). 


\section{9 a 22 de outubro de 2014 \\ Florianópolis/SC}

Quando se considera a produção de biocombustíveis, o fato de a secagem permitir a estocagem da biomassa por longos períodos, facilitar o transporte e facilitar a cominuição desta em moinhos comumente usados em escalas industriais, percebe-se que esta estratégia torna-se interessante, mesmo que as etapas seguintes sejam a reidratação do material para a produção de açúcares via processos biológicos (Rivers et al., 1987; Digman et al., 2010; Ewanick et al., 2011).

O processamento de uma biomassa para obtenção de açúcares geralmente passa pelas seguintes etapas: cominuição, pré-tratamento e hidrólise enzimática. O teor de água presente na biomassa poderá influenciar fortemente na energia gasta na etapa de cominuição. No estudo realizado por Barakat et al. (2013), verificou-se que um aumento de até $50 \%$ na energia gasta na etapa de cominuição pode ocorrer quando a umidade do material aumenta de $10 \%$ para $15 \%$. Apesar das vantagens do uso de biomassa com baixo teor de água na etapa de cominuição, nas etapas seguintes do processamento isto poderá ter um efeito negativo (Ewanick et al., 2011). Entretanto, o uso de um pré-tratamento adequado poderá neutralizar tais efeitos.

O pré-tratamento de biomassas é aplicado para a remoção ou modificação de componentes indesejados da biomassa visando o aumento da velocidade e rendimentos em açúcares via hidrólise enzimática (Mosier et al., 2005). Neste trabalho, o pré-tratamento utilizado envolveu uma etapa usando ácido para remoção de hemicelulose e uma etapa alcalina para remoção de lignina, ambos com o objetivo de facilitar o acesso das celulases ao substrato por meio do intumescimento e aumento da porosidade do material (Xu et al., 2011; Kim et al., 2012).

A escolha do pré-tratamento é importante, mas é preciso manter em mente que a possibilidade de reidratação do material para facilitar a hidrólise enzimática dependerá de vários fatores, entre eles, tamanho de partícula da biomassa, temperatura de secagem, valor final de umidade, estrutura e composição química da biomassa (Cullis et al., 2003; Acharjee et al. 2011; Luo et al. 2011; Zhang et al., 2013). No estudo realizado por Maache-Rezzoug et al. (2011), observou-se que uma variação de 10 a $40 \%$ no teor de água da palha de trigo não afeta a hidrólise enzimática, desde que esta matériaprima seja previamente submetida a tratamento a vapor.

A biomassa pode estar envolvida pela água em diferentes níveis, por exemplo, em níveis moleculares (água ligada aos diferentes componentes) e macromoleculares (entre os poros e livre). Em cada um dos casos a água tem propriedades distintas, mas ambas fundamentais na interação enzima-substrato (Kristensen et al., 2009). Dependendo da composição do material pré-tratado, diferentes quantidade e distribuição de água podem ser observadas, pois a água se liga de maneira diferente aos diferentes componentes da biomassa, por exemplo, hemicelulose tem alta capacidade de ter água ligada, enquanto celulose e lignina não a têm (Modenbach et al., 2012).

Considerando o exposto, o objetivo deste trabalho foi estudar o efeito da secagem de biomassa sobre o pré-tratamento químico e a hidrólise enzimática. A Brachiaria brizantha foi utilizada como biomassa modelo, pois apresenta elevado potencial de produção, podendo atingir 18 ton/MS/ha/ano (Sá et al., 2010), a um baixo custo e, além disso, também apresenta baixo teor de lignina, o que tem despertado o interesse científico para estudos de melhoramento e aplicação desta biomassa na produção de biocombustíveis (Carvalho et al., 2011). 


\section{MATERIAIS E MÉTODOS}

\subsection{Materiais}

Os principais materiais utilizados neste trabalho foram: a forrageira Brachiaria brizantha cv. Marandu (produzida em campos da Embrapa Cerrados), o extrato enzimático comercial Cellic ${ }^{\circledR}$ CTec2, da Novozymes, o qual tem atividade $\cong 147 \mathrm{FPU} / \mathrm{mL}$. Os equipamentos utilizados foram moinho IKA modelo A11, estufa, mesa agitadora e cromatógrafo a líquido da Agilent Infinity 1260.

\subsection{Métodos}

Para visualizar a estrutura deste trabalho, um fluxograma com as principais etapas realizadas são apresentadas na Figura 1, e em seguida é apresentada uma descrição detalhada destas etapas.

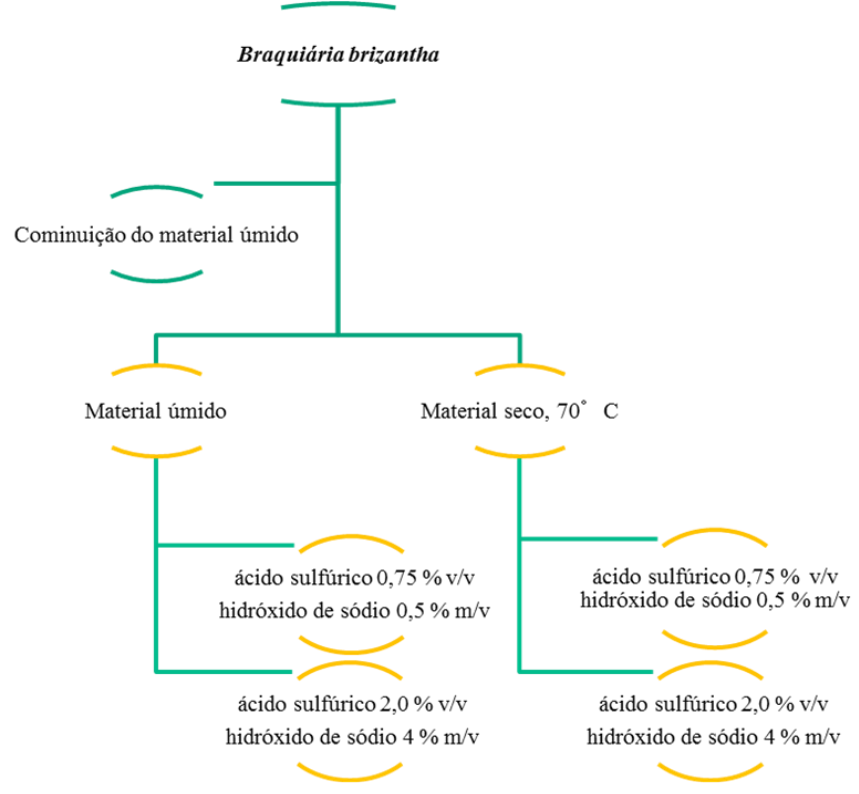

Figura 1 - Fluxograma das etapas de preparo da biomassa para a hidrólise enzimática. Cada um dos blocos amarelos representa uma amostra gerada.

Cominuição do material úmido: A eficácia do pré-tratamento e hidrólise enzimática depende do tamanho de partícula inicial da matéria-prima. Assim, para que a única diferença entre as amostra geradas fosse o teor de água, a biomassa foi cominuída ainda úmida e depois dividida em duas frações, uma que permaneceu úmida e outra que foi seca a $70^{\circ} \mathrm{C}$. Para moagem do material úmido foi utilizado um moinho modelo A11 basic da IKA, com rotação de $28000 \mathrm{rpm}$ por 30 segundos.

Pré-tratamento: O pré-tratamento foi realizado em duas etapas, primeiramente com solução de ácido sulfúrico e em seguida com solução de hidróxido de sódio. A razão sólido:líquido em todas as condições de pré-tratamento foi de $1: 10 \mathrm{~m} / \mathrm{v}$. As frações úmida e seca da biomassa, foram submetidas a pré-tratamento fraco (ácido sulfúrico $0,75 \%$ v/v seguido de hidróxido de sódio 0,5\% m/v) e pré- 


\section{9 a 22 de outubro de 2014 \\ Florianópolis/SC}

tratamento forte (ácido sulfúrico $1,5 \%$ v/v seguido de hidróxido de sódio $4 \% \mathrm{~m} / \mathrm{v}$ ). Em todas as etapas, as amostras foram mantidas por 30 minutos em autoclave a $121^{\circ} \mathrm{C}$. Após a etapa ácida, cada material foi lavado com água destilada e o procedimento em autoclave repetido, desta vez usando solução de hidróxido de sódio. Ao final desta etapa o material foi lavado com água destilada fervente.

Caracterização das amostras in natura e pré-tratadas de Brachiaria brizantha: Todas as amostras de Brachiaria brizantha (úmida, seca, úmida e seca submetidas a pré-tratamento fraco, úmida e seca submetidas a pré-tratamento forte) foram caracterizadas quanto ao teor de umidade. Além disso, foi utilizada metodologia descrita por Gouveia et al. (2009) para estimar os percentuais de celulose e hemicelulose nestas amostras.

Hidrólise enzimática: a razão sólido:líquido nas reações de hidrólise enzimática foi de 0,025:1, $\mathrm{m} / \mathrm{v}$. A reação foi conduzida em mesa agitadora (shaker) a $50{ }^{\circ} \mathrm{C}$ e $200 \mathrm{rpm}$, na presença de tampão citrato $100 \mathrm{mM}, \mathrm{pH}$ 5. A quantidade de enzima utilizada em cada erlenmeyer foi de $30 \mathrm{FPU} / \mathrm{g}$ de celulose. Estes experimentos foram realizados em triplicata. A quantidade de glicose liberada após 48 $\mathrm{h}$ de reação foi determinada por cromatografia líquida de alta eficiência (CLAE).

\section{RESULTADOS E DISCUSSÃO}

Os resultados obtidos neste estudo serão apresentados e discutidos nos dois itens a seguir, os quais tratam da caracterização da biomassa quanto ao percentual de cada polissacarídeo (celulose e hemicelulose) e teor de umidade e, além disso, apresentam os dados de desempenho na hidrólise de cada uma das amostras geradas.

\subsection{Caracterização de Brachiaria brizantha in natura e pré-tratadas}

A determinação dos teores de umidade da biomassa in natura (úmida e seca) e dos materiais obtidos após cada etapa de pré-tratamento foram fundamentais para definir a quantidade de massa úmida a ser pesada, de tal forma que em cada etapa reacional de pré-tratamento ou hidrólise enzimática, uma quantidade padronizada de massa seca da biomassa fosse adicionada aos reatores. Além disso, estes dados também permitiram a avaliação da eficácia dos pré-tratamentos e hidrólises enzimáticas dos diferentes amostras geradas. A Tabela 1 apresenta os dados de umidade.

Tabela 1 - Dados de umidade medidos em Brachiaria brizantha após diferentes tratamentos

\begin{tabular}{c|c}
\hline Amostras de Brachiaria (após moagem) & Teor de umidade (\%) \\
\hline In natura (Úmida) & $66,16 \pm 1,1$ \\
In natura após secagem a $70^{\circ} \mathrm{C}$ (Seca) & $5,53 \pm 0,0$ \\
Úmida submetida a pré-tratamento fraco & $71,55 \pm 2,0$ \\
Úmida submetida a pré-tratamento forte & $78,71 \pm 1,3$ \\
Seca submetida a pré-tratamento fraco & $75,90 \pm 0,4$ \\
Seca submetida a pré-tratamento forte & $79,44 \pm 0,8$ \\
\hline
\end{tabular}

Em função da drástica redução no teor de umidade após a secagem da biomassa (de $66 \%$ para 5 $\%$ ), é possível observar uma mudança no aspecto físico do material, como mostra a Figura 2 (B e E). 
Apesar de o aspecto físico demostrar apenas uma ligeira modificação na coloração do material, a secagem a $70{ }^{\circ} \mathrm{C}$ torna a biomassa mais "quebradiça", o que é importante para a cominuição do mesmo, por exemplo, por meio de processos mecânicos. Por outro lado, este procedimento dificulta significativamente a etapa de hidrólise enzimática, como será apresentado no item a seguir.

Após os pré-tratamentos fracos tanto do material úmido quanto do material seco, foi observado um aumento no teor de umidade $(71$ e 76 \%) em relação à umidade no material de partida (Brachiaria brizantha moída com $66 \%$ de umidade). Vale ressaltar que estes valores foram medidos após lavagem e prensagem do material pré-tratado até que não fosse observada extração de água. Quando pré-tratamento forte foi aplicado os valores de umidade foram ainda ligeiramente aumentados (79\%).

Este resultado parece contradizer dados da literatura, pois é esperado um aumento da hidrofobicidade do material pré-tratado, ou seja, menor teor de água ligado a este. Algumas considerações precisam ser mencionadas, por exemplo, em relação aos tipos de água presentes na biomassa. Como a fração que apresenta maior tendência a manter água ligada, a hemicelulose, foi retirada, é esperado que o aumento no teor de água dos materiais pré-tratados se justifique pelo aumento da porosidade do material após a remoção da hemicelulose e lignina. Além disso, as alterações causadas na celulose devido à ação do hidróxido de sódio também provocaram o intumescimento deste sólido. Considerando as mudanças nos aspectos físicos após os pré-tratamentos, a Figura 2 apresenta fotos em que visivelmente é possível perceber o efeito da severidade nestes processos.

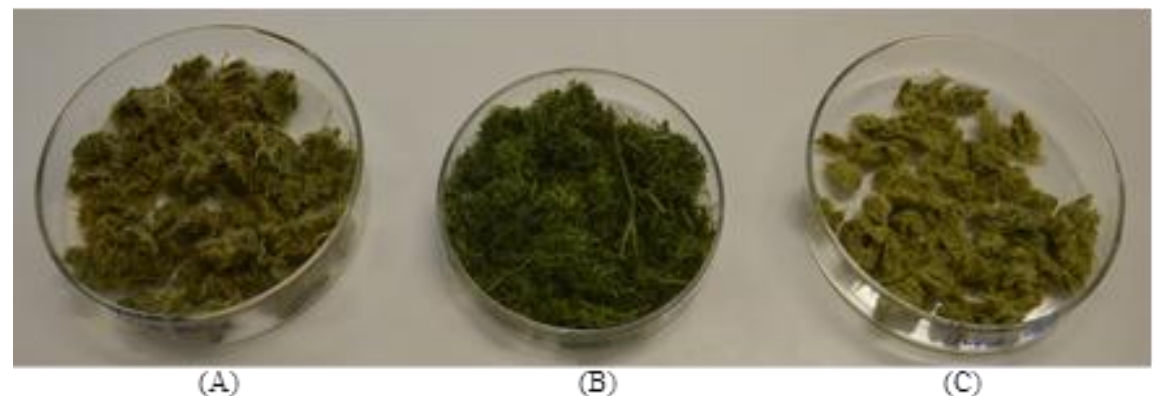

(A)

(B)

(C)

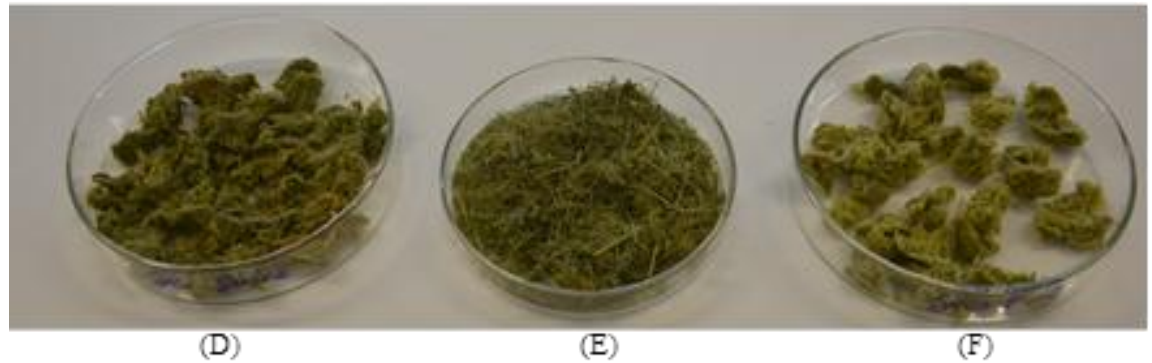

Figura 2 - Foto das seis amostras de Brachiaria brizantha geradas sob diferentes tratamentos para serem submetidas à hidrólise enzimática. (A) Úmida submetida a pré-tratamento fraco, (B) In natura (Úmida), (C) Úmida submetida a pré-tratamento forte, (D) Seca submetida a pré-tratamento fraco, (E) In natura após secagem a $70{ }^{\circ} \mathrm{C}$ (Seca), (F) Seca submetida a pré-tratamento forte. 
Visualmente, é possível perceber que tanto em materiais pré-tratados a partir de amostra úmida quanto a partir de amostra seca, ocorre redução no tamanho das fibras na seguinte sequência: tamanho de fibras na amostra in natura (seca ou úmida) > tamanho de fibras nas amostras submetidas a prétratamento fraco > tamanho de fibras nas amostras submetidas a pré-tratamento forte. Amostras submetidas à pré-tratamento forte tem um aspecto mais homogêneo em relação às demais amostras.

\subsection{Hidrólise enzimática de Brachiaria brizantha in natura e pré-tratadas}

As amostras descritas acima foram caracterizadas quanto ao teor de celulose e hemicelulose, e experimentos de hidrólise enzimática foram realizados utilizando o extrato enzimático Cellic Ctec ${ }^{\circledR}$ 2. Os resultados são apresentados na Tabela 2.

Tabela 2 - Dados dos percentuais de celulose e hemicelulose em brachiaria pré-tratada

\begin{tabular}{c|c|c}
\hline Amostras de Brachiaria brizantha & $\%$ de celulose & $\%$ de hemicelulose \\
\hline In natura (Úmida) & $30,88 \pm 1,7$ & $19,61 \pm 2,1$ \\
In natura após secagem a $70^{\circ} \mathrm{C}$ (Seca) & $30,88 \pm 1,7$ & $19,61 \pm 2,1$ \\
Úmida submetida a pré-tratamento fraco & $57,21 \pm 1,5$ & $14,81 \pm 0,5$ \\
Úmida submetida a pré-tratamento forte & $88,56 \pm 0,1$ & $4,42 \pm 0,1$ \\
Seca submetida a pré-tratamento fraco & $61,29 \pm 3,4$ & $13,27 \pm 0,5$ \\
Seca submetida a pré-tratamento forte & $86,66 \pm 0,7$ & $4,37 \pm 0,2$ \\
\hline
\end{tabular}

Conhecendo o teor de umidade e o percentual de celulose em base seca de cada uma das amostras da Tabela 2, a quantidade de cada um destes materiais a ser adicionada ao reator foi calculada de tal forma que a concentração final máxima de glicose, em caso de hidrólise completa, atingisse $25 \mathrm{~g} / \mathrm{L}$. O gráfico da Figura 3 apresenta os dados de concentração de glicose obtidos para cada uma das amostras. A quantidade de enzima utilizada em cada reator foi de $30 \mathrm{FPU} / \mathrm{g}$ de celulose e a reação ocorreu por $48 \mathrm{~h}$.

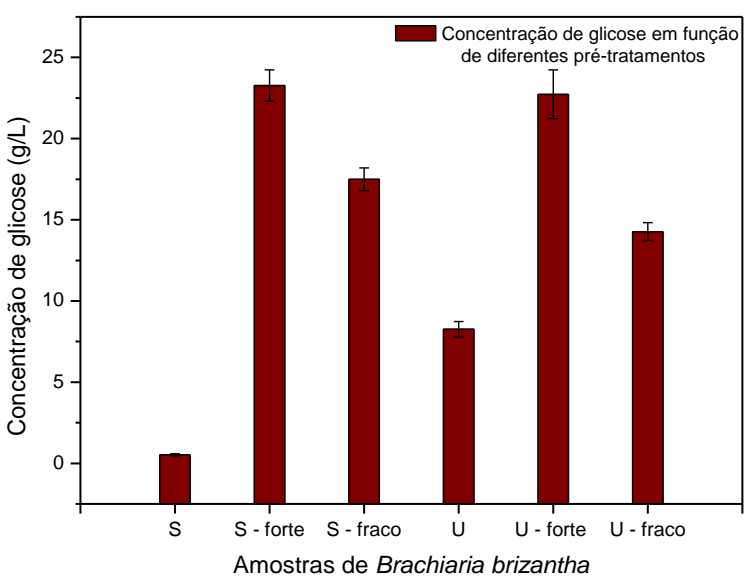

Figura 3 - Dados da hidrólise de brachiaria. S representa amostra seca; U, úmida; Forte, prétratamento forte e Fraco, pré-tratamento fraco. 
Na Figura 3 percebe-se que a secagem interfere fortemente na eficácia de hidrólise dos materiais in natura (amostras seca e úmida), mas que após o pré-tratamento químico fraco e forte os rendimentos de hidrólise são similares.

\section{CONCLUSÃO}

A secagem de biomassa é importante para facilitar o transporte e armazenamento desta. Entretanto, isto causa um efeito negativo na hidrólise enzimática, o que leva a necessidade de um prétratamento eficaz para viabilizar a hidrólise enzimática. O pré-tratamento químico usando ácido sulfúrico e hidróxido de sódio em elevadas concentrações é uma das estratégias eficazes para reduzir a recalcitrância da amostra favorecendo o aumento no rendimento na produção de açúcares em processos de hidrólise enzimática.

\section{REFERÊNCIAS}

ACHARJEE, T.C.; CORONELLA, C.J.; VASQUEZ, V.R. Effect of thermal pretreatment on equilibrium moisture content of lignocellulosic biomass. Bioresour. Technol., v. 102, p. 48494854, 2011.

ATHMANATHAN, A., MOSIER, N.S. Effect of storage method and duration on the bioprocessing of lignocellulosic biomass (2011). Disponível em: http://www.aiche.org/cei/resources/chemeondemand/conference-presentations/effect-storagemethod-and-duration-bioprocessing-lignocellulosic-biomass. Acessado em: 28/04/2014.

BARAKAT, A.; VRIES, H.D.; ROUAU, X. Dry fractionation process as an important step in current and future lignocellulose biorefineries: A review. Bioresour. Technol, v. 134, p. 362-373, 2013.

CARVALHO, F.B.P.; PACHECO, T.F.; D.S. RODRIGUES, GONÇALVES, S.B., CARVALHO, M.A.; C.M.M. MACHADO. Produção de Etanol a partir da forrageira Brachiaria Brizantha cv. Marandu. XVIII Simpósio Nacional de Bioprocessos, Caxias do Sul - RS, 2011.

CULLIS, I.F.; SADDLER, J.N.; MANSFIELD, S.D. Effect of initial moisture content and chip size on the bioconversion efficiency of softwood lignocellulosics. Biotechnol. Bioeng., v. 85, n. 4, p. 413-421, 2004.

DIGMAN, M.F.; SHINNERS, K.J.; CASLER, M.D.; DIEN, B.S.; HATFIELD, R.D.; JUNG, H-J.G.; MUCK, R.E.; WEIMER, P.J. Optimizing on-farm pretreatment of perennial grasses for fuel ethanol production. Bioresour. Technol., v. 101, p. 5305-5314, 2010.

EWANICK, S.; BURA, R. The effect of biomass moisture content on bioethanol yields from steam pretreated switchgrass and sugarcane bagasse. Bioresour. Technol., v. 102, p. 2651-2658, 2011.

KIM, S.; PARK, J.M.; SEO, J.-W.; KIM, C.H. Sequential acid-/alkali-pretreatment of empty palm fruit bunch fiber. Bioresour. Technol., v. 109, p. 229-233, 2012. 
KRISTENSEN, J.B. Enzymatic hydrolysis of lignocellulose Substrate interactions and high solids loadings (2009). Disponível http://curis.ku.dk/ws/files/20572426/nr_42_phd_janweb.pdf. Acessado em: 28/04/2014.

LI, Y.; SHI, J.; REEDER, R. Storing Lignocellulosic Biomass for Bio-Refining Industry. The Ohio State University (2011). Disponível em: http://ohioline.osu.edu/aex-fact/pdf/0651.pdf. Acessado em: 28/04/2014.

LUO, X.; ZHUB, J.Y. Effects of drying-induced fiber hornification on enzymatic saccharification of lignocelluloses. Enzyme Microb. Technol., v. 48, p. 92-99, 2011.

MAACHE-REZZOUG, Z.; PIERRE, G.; NOUVIAIRE, A.; MAUGARD, T.; REZZOUG, S.A. Optimizing thermomechanical pretreatment conditions to enhance enzymatic hydrolysis of wheat straw by response surface methodology. Biomass and Bioenergy, v 35, p 3129-3138, 2011.

MEDIC, D.; DARR, M.; SHAH, A.; POTTER, B.; ZIMMERMAN, J. Effects of torrefaction process parameters on biomass feedstock upgrading. Fuel, v. 91, p. 147-154, 2012.

MIAO, Z.; SHASTRI, Y.; GRIFT, T.E.; HANSEN, A.C.; TING, K.C. Lignocellulosic biomass feedstock transportation alternatives, logistics, equipment configurations, and modeling. Biofuels, Bioprod. Bioref., v. 6, p. 351-362, 2012.

MODENBACH, A.A; NOKES, S.E. The use of high-solids loadingis in biomass pretreatment - A review. Biotechnol. Bioeng., v. 109, n. 6, p. 1430-1442, 2012.

MOSIER, N.; WYMAN, C.; DALE, B.; ELANDER, R.; LEE, Y.Y.; HOLTZAPPLE, M.; M. LADISCH. Features of promising technologies for pretreatment of lignocellulosic biomass. Bioresour. Technol., v. 96, p. 673-686, 2005.

RIVERS, D.B.; EMERT, G.H. Lignocellulose pretreatment: a comparison of wet and dry ball attrition. Biotechnol. Lett., v. 9, n. 5, p. 365-368, 1987.

SÁ, J.F.; PEDREIRA, M.S.; SILVA, F.F.; BONOMO, P.; FIGUEIREDO, M.P.; MENEZES, D.R.; ALMEIDA, T.B. Fracionamento de carboidratos e proteínas de gramíneas tropicais cortadas em três idades. Arq. Bras. Med. Vet. Zootec., v.62, n.3, p.667-676, 2010.

XU, J.; CHENG, J.J. Pretreatment of switchgrass for sugar production with the combination of sodium hydroxide and lime. Bioresour. Technol., v. 102, p. 3861-3868, 2011.

ZHANG, W.; YI, Z.; HUANG, J.; LI, F.; HAO, B.; LI, M.; HONG, S.; LV, Y.; SUN, W.; RAGAUSKAS, A.; HUF, F.; PENG, J.; PENG, L. Three lignocellulose features that distinctively affect biomass enzymatic digestibility under $\mathrm{NaOH}$ and $\mathrm{H}_{2} \mathrm{SO}_{4}$ pretreatments in Miscanthus. Bioresource Technology 130 (2013) 30-37. 